\title{
GIS Utilization for Delivering a Time Condition Products
}

\author{
Noha I. Sharaf \\ Information System Dept \\ Faculty of Computers and \\ Information Science \\ Mansoura, Egypt
}

\author{
Bahaa T. Shabana \\ Computer Sciences Dept \\ Misr Higher Institute for Commerce \\ \& Computer \\ Mansoura, Egypt
}

\author{
Hazem M. El-Bakry \\ Information System Dept \\ Faculty of Computers and \\ Information Science \\ Mansoura, Egypt
}

\begin{abstract}
As population is increasing rapidly all over the world, the need for delivering products is being more difficult especially for conditional products (products with life time). Many Customers require conditional products to be delivered to their locations. Distribution center may have multi depots (multi store branches) instead of one depot. Every depot has limited number of vehicles to minimize cost. Capacities of these vehicles are based on two dimensions (weight and volume). Geographic information system (GIS) is used for localizing customers' destinations. Then OD Cost Matrix is used to assign every customer destination to the least cost depot to be served from it. Finally Network analyst is used to solve the vehicle routing problem generating final route directions for every vehicle and calculating the best time for lunch break of drivers automatically. This case study is applied on Mansoura city in Egypt.
\end{abstract}

Keywords - conditional products; distribution centers (depots); capacity of vehicle; vehicle routing problems (VRP); geographic information system (GIS); OD Cost Matrix; Network analyst

\section{INTRODUCTION}

As demands on conditional products are increasing very rapidly all over the world, the transportation of deliveries is being a hard process. Traditional ways used in delivering conditional products depending on experience of the drivers. In many situations, it is not efficient way as long as many customers requesting many products from the same depot. These products have a life time and must be delivered within it. Having many factors in consideration, like capacity of limited vehicles which is based on two dimensions (weight and volume), calculating the time of break for every driver, life time of products, sequence of delivering products matching minimum cost, travel distance and travel time without violating time constraints. To minimize travel distance and total time, vehicles should visit the customer's location only one time. Vehicles start and end on same depot. Customers are clustered according to geographical zone. Assumed, all depots are huge enough to have all requested products. To minimize cost, products with small life time should be delivered faster than others so as not to spoil. A driver working hours is set to be 6 hours per day. Working more than 6 hours is calculated as overtime. Total cost is calculated by cost of the drivers' working hours, overtime hours and fuel cost consumptions in the transportation. GIS tools help in solving the problem of delivering conditional products. AS GIS use spatial data [1] (geographical data) and attribute data [2] especially in road networks [3]. GIS proved its efficiency in many applications such as transportation (GIS-T) [4] , finding best route, traffic and road congestion problems [5] intelligent transportation systems (ITS), scheduling and routing school buses [6], Travelling sales man (TSP), Vehicle routing problems (VRP) as it is considered an extension of TSP [7] and supply chain management. In this paper, GIS tools and network analyst are used to solve problem of delivering conditional products within its life time to customers located in Mansoura city in Egypt and determining the suitable time for drivers break automatically.

\section{LITERATURE REVIEW}

Surekha P and S.Sumathi used Genetic Algorithm (GA) to solve the problem of Multi-Depot Vehicle Routing Problem (MDVRP). Then, they used Clarke and Wright saving Method in routing using MATLAB R2008b software. In this paper, OD cost matrix and Network Analyst VRP is used to solve the problem of transporting deliveries from the least cost depot to customers' destinations without violating lifetime constraints of products using ArcMap 9.3 software.

Rong-Chang Chen, Chih-Hui Shieh, Kai-Ting Chan, ShinYi Chiu, Jyun-You Fan, Yu-Ting Chang and Nuo-Jhen Ma introduced systematic approach for solving the problem of delivering Service for Bento Industry based on three-stage approach. They used GIS for locating customers' locations. Then, they used K-means algorithm for clustering. Finally, they used Genetic algorithm (GA) to get the shortest route with shortest travel distance. In this paper, Network Analyst is used instead of GA and OD cost Matrix is used to assign requested orders to be delivered from least cost depot to minimize total cost. In addition to, the system is determining the break time of drivers based on products assigned to their schedule.

Hari Shankar, Gangesh Mani, Kamal Pandey used Tabu search algorithm with GIS to solve the multi depot vehicle routing problem with time window (MDCVRPTW) in capital city Dehradun of Uttrakhand state. They considered many parameters with predefined static break time. In this paper, break time of every driver is calculated automatically according to his schedule without violating products' lifetime and vehicles constraints.

M.Abousaeidi, R.Fauzi and R.Muhamad used GIS to find the fastest delivery route not the shortest route as the shortest route may not be the optimal route. GIS based on VRP was used by V.K.Purwar, Varun Singh and R.C. Vaishya to solve 
milk distribution problem in Allahabad city. In this paper, GIS used to find the route delivering all conditional products within lifetime with minimum total cost by using OD Cost Matrix.

In this paper, GIS tools are used to solve the problem of Multi depot vehicle routing problem (MDVRP) for conditional products with life time in Mansoura city in Egypt. Minimizing, total cost and travel distance during visiting all the required regions (Customers' destinations). Travelling to every customer's destination from the nearest least cost depot. Generating routes with directions and calculating the proper time for lunch break of every driver automatically based on his schedule.

\section{PROBLEM DEFINITION}

Main problem is delivering all requested conditional products to customers without violating constraints with minimum total cost and calculating drivers' lunch break automatically. Using Systematic approach based on GIS tools (ArcGIS software) instead of traditional ways to transmit requested orders to customers' locations from the nearest least cost depot. Not the depot where received the customers' request. As customer can make request from any depot. But it must be served from the nearest depot with the least cost. This case study is applied in Mansoura city in Egypt.

\section{A. Proposed Constraints}

Customers make orders requesting conditional products with varying lifetime. Products must be delivered within its life time to be valid to be used. Every Customer's order cannot be composed into different vehicles [8].

To minimize total cost, depots have limited number of vehicles. Customer's location should be visited only one time and served from the nearest depot even though the requested order was from any other depot. Capacities of vehicles transmitting orders are based on two dimensions weight and volume and have assumed to be 6000[9], [10]. Vehicles start and end on same depot. Having restrictions over visiting routes according to their geographical places (route Zones). Number of depots and vehicles are limited (assumed having 2 multidepots with multi vehicles). All depots are huge enough to store all types of products. Customer's demand is being served from the least cost depot to minimize travel cost and travel distance [11]. Drivers working hours cost are assumed to be 12 EGP per hour and over time is calculated after working more than 6 hours and is assumed to be 18 EGP per hour. Availability time of vehicles, drivers and depots are proposed to start from 8:00 AM to 5:00 PM. Drivers must have a dynamic payable period for lunch break instead of static time break based on different policies of different companies. Starting time and ending time of lunch break is calculated automatically. Managing total cost of transportation to be minimized including factors of driving cost per hour, overtime driving cost per hour, fuel consumption cost which is calculated by the travel distance cost per Mile. Including gained revenue from delivering orders. Route directions of vehicles are changed automatically according to occurred barriers [12].

\section{B. Expected Result}

Giving every driver the best route directions including time of his lunch break calculated automatically without violating any constraints from the proposed constraints with minimum total cost in distance and time as much as possible.

\section{Data Collection}

- Streets collected from world street map as a layer into ArcMap 9.3[13].

- Geo-database designed on ArcCatalog.

- Data projection applied on world street map layer with Projected coordinate system WGS _1984 _UTM_Zone_36N

\section{Database in details}

This case study is applied on random region in Mansoura city in Egypt as shown in Fig 1. Assumed, having, 13 customer requesting 6 different conditional products from two center depots. Mansoura city is not huge enough but has heavy congestion which makes delivering conditional products hard process to be achieved optimally.

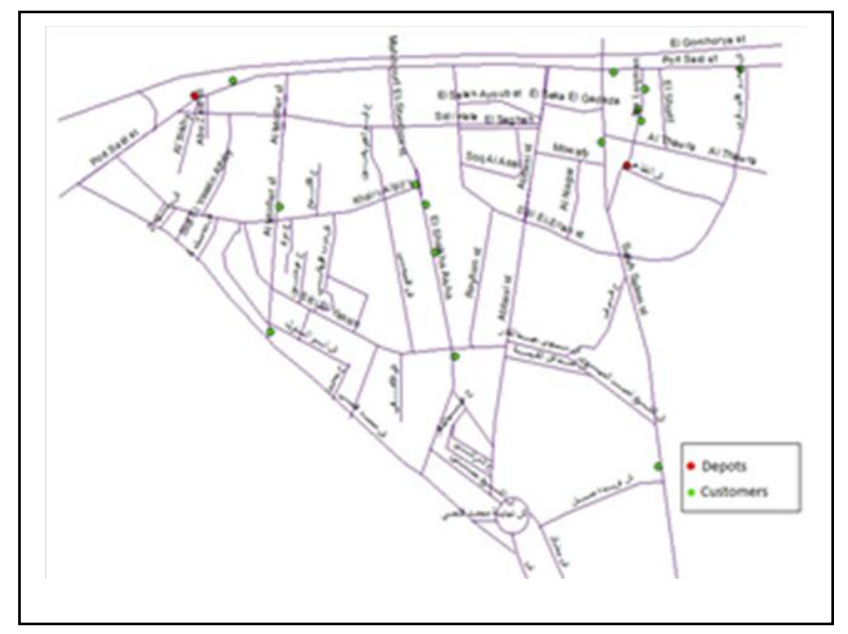

Fig. 1. Random selected area in Mansoura city in Egypt

Geo-database contains dataset with feature classes of streets as polyline type and depots as point type [14]. Properties of streets and center depots feature classes are represented in table I and table II consequently. Used Network Dataset is shown in Fig 2. 
TABLE I. PROPERTIES OF STREETS

\begin{tabular}{|l|l|}
\hline Field Name & Data Type \\
\hline OBJECTID & Object ID \\
\hline SHAPE & Geometry \\
\hline NAME & Text \\
\hline TYPE & Text \\
\hline Oneway & Text \\
\hline FT_Minutes & Double \\
\hline TF_Minutes & Double \\
\hline SHAPE_Length & Double \\
\hline houseFromL & Short Integer \\
\hline houseFromR & Short Integer \\
\hline houseToL & Short Integer \\
\hline houseToR & Dort Integer \\
\hline TF_Speed & Double \\
\hline
\end{tabular}

Fig. 2. Network Dataset of the selected region

TABLE II. PROPERTIES OF DEPOTS

\begin{tabular}{|l|l|}
\hline Field Name & Data Type \\
\hline OBJECTID & Object ID \\
\hline SHAPE & Geometry \\
\hline StoreName & Text \\
\hline StartTime & Date \\
\hline CloseTime & Date \\
\hline
\end{tabular}

E. Steps of solving the problem

Step1: Designing geo-database in ArcCatalog.

Step2: Collecting or writing assumed data from customers (customers' demands).

\section{Step3: For all customers}

3.1 Check if customer's demand was not from nearest depot

3.2 Use OD cost Matrix on network analyst in ArcMap to get nearest least cost depot [15].

Step4: Adding all proposed constraints.

Step5: Using network analyst vehicle routing problem to solve the problem [16]

Step6: Output result (generating routes with directions and calculating proper time of dynamic launch break).
Step7: If there is barrier occurred in resulting route directions (street)

\subsection{Repeat steps 5, 6}

Else print directions windows of all routes

\section{SyStem'S INPUT DATA}

Assumed proposed input data properties are shown in table III, table IV consequently. Attributes of the customers' orders table are customer name, customer address, product Name, depot address which represents address of depot that received the customer demand, order time which is time of requesting the product, Product LifeTime which is the end time of life time of the requested product, total orders which is the total number of requested orders, revenue per unit, total revenue, unit weight, unit volume, total weight, total volume, total quantities as is represented on two dimensions (weight and volume), maximum transmission time in minutes and specialty name as some products need a foodkeeper to save its temperature so as not to spoil like an ice-cream.

Attributes of drivers' lunch break table are RouteName as break is calculated separately based on every route, serviceTime as it is varying between companies based on their internal policies. Starting time and ending time are set to be NULL to be calculated by the system based on conditional products of each route.

TABLE III. PROPERTIES OF CUSTOMERS' ORDERS

\begin{tabular}{|l|l|}
\hline Field Name & Data Type \\
\hline ID & Object ID \\
\hline CustomerName & Text \\
\hline CustomerAddress & Text \\
\hline ProductName & Text \\
\hline DepositAddress & Text \\
\hline OrderDate & DateTime \\
\hline Product LifeTime & DateTime \\
\hline TotalOrders & Short Integer \\
\hline UnitRevenue & Double \\
\hline TotalRevenue & Double \\
\hline UnitWeight & Double \\
\hline UnitVolume & Double \\
\hline TotalWeight & Double \\
\hline TotalVolume & Double \\
\hline TotalQuantities & Double \\
\hline MaxTransitTime & DateTime \\
\hline SpecialtyName & Text \\
\hline
\end{tabular}

TABLE IV. PROPERTIES OF DRIVERS' LUNCH BREAK

\begin{tabular}{|l|l|}
\hline Field Name & Data Type \\
\hline RouteName & Text \\
\hline ServiceTime & DateTime \\
\hline StartTime & DateTime \\
\hline EndTime & DateTime \\
\hline
\end{tabular}

\section{SYSTEM'S OUTPUT}

For every customer, the nearest depot should be specified to get requested products from it and deliver them to customers. OD Cost Matrix in ArcMap is used to determine the least cost depot from all customers' locations as shown in Fig 3. 


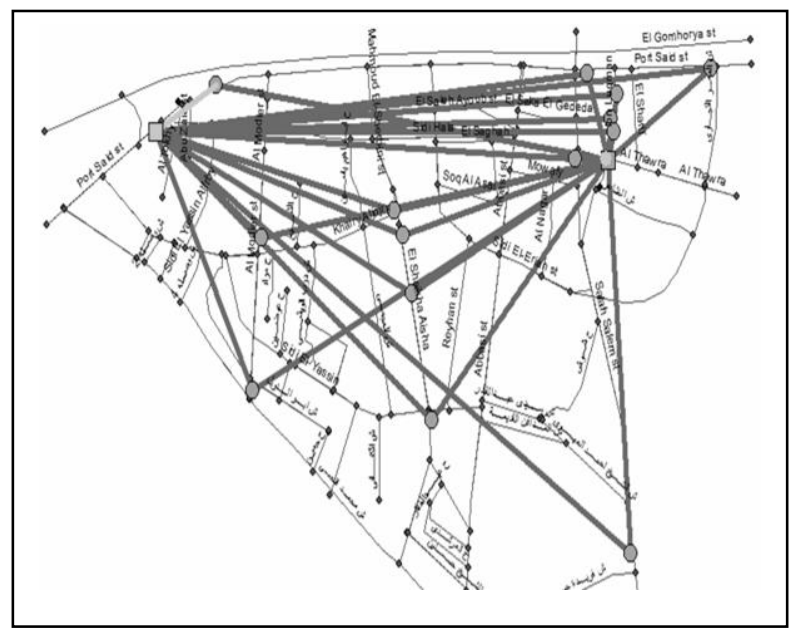

Fig. 3. Result of OD Cost Matrix

As assumed, having 2 depots (left and right) and received 14 orders. The Output result is 28 lines. Every customer's order is represented in two rows. Each row representing Rank destination, total minutes (cost of traveling along the network) from customer destination to every depot (the left and right depot). The least cost depot has rank 1 as shown in Fig 4. For example Travel cost from Nancy destination to left depot is 0.65 minutes, and travel cost from Nancy destination to right depot is 7.2 minutes. So, rank value 1 is given to left depot (left store) and Nancy order is collected from the left depot (the least cost depot) and so on.

\begin{tabular}{|c|c|c|c|c|c|c|}
\hline \multicolumn{3}{|c|}{ ttributes of lines } & \multicolumn{2}{|l|}{1} & 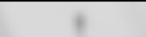 & 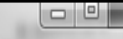 \\
\hline ObjectlD & Shape & Name & OriginlD & DestinationlD & DestinationRank & Total_Minutes \\
\hline 57 & Polyine & Nancy (Home) - Left strore & 17 & 18 & 1 & 0.655376 \\
\hline 58 & Polyine & Nancy (Home) - Right store & 17 & 19 & 2 & 7.258508 \\
\hline 59 & Polyine & Hend (Home) - Right store & 18 & 19 & 1 & 1.139772 \\
\hline 60 & Polyine & Hend (Home) - Left strore & 18 & 18 & 2 & 5.720807 \\
\hline 61 & Polyine & Heba (Home) - Left strore & 19 & 18 & 1 & 1.865804 \\
\hline 62 & Polyine & Heba (Home) - Right store & 19 & 19 & 2 & 6.361728 \\
\hline 63 & Polyine & Samy (Home) - Right store & 20 & 19 & 1 & 0.338936 \\
\hline 64 & Polyine & Samy (Home) - Left strore & 20 & 18 & 2 & 7.026742 \\
\hline 65 & Polyine & Basem (Home) - Left strore & 21 & 18 & 1 & 2.018723 \\
\hline 66 & Polyine & Basem (Home) - Right store & 21 & 19 & 2 & 6.208809 \\
\hline 67 & Polyine & Manar (Home) - Right store & 22 & 19 & 1 & 1.361076 \\
\hline 68 & Polyine & Manar (Home) - Left strore & 22 & 18 & 2 & 7.274 \\
\hline 69 & Polyine & Nawal (Home) - Right store & 23 & 19 & 1 & 0.207879 \\
\hline 70 & Polyine & Nawal (Home) - Left strore & 23 & 18 & 2 & 7.068458 \\
\hline 71 & Polyine & Ali (Home) - Left strore & 24 & 18 & 1 & 2.251741 \\
\hline Record: 14 & & $1 \cdot \|$ & & ds (2 out of $28 \mathrm{Se}$ ) & Opto & \\
\hline
\end{tabular}

Fig. 4. Result of OD Cost Matrix

The Output of OD Cost Matrix is used as an input into network analyst VRP. After using the vehicle routing problem in network analyst in ArcMap 9.3. Every order is assigned to only one vehicle to be delivered to the customer. Routes with directions of vehicles are also determined without violating all proposed constraints.

Route properties are shown in Fig 5. Capacity of vehicles is proposed to be 6000 for weight and 6000 for volume. Cost per unit variable is set to 12 EGP per hour. By dividing 12/60 equals 0.2. Cost per unit time equals 0.2 .Over time starts after working 6 hours so it is set to be 360 (6hours * 60 minute).
Cost per unit over time is set to be 18 EGP per hour. By dividing 18/60 equals 0.3 . After solving the problem with no barrier, calculated fields of routes are shown in Fig 6 and Fig 7 consequently without time violation.

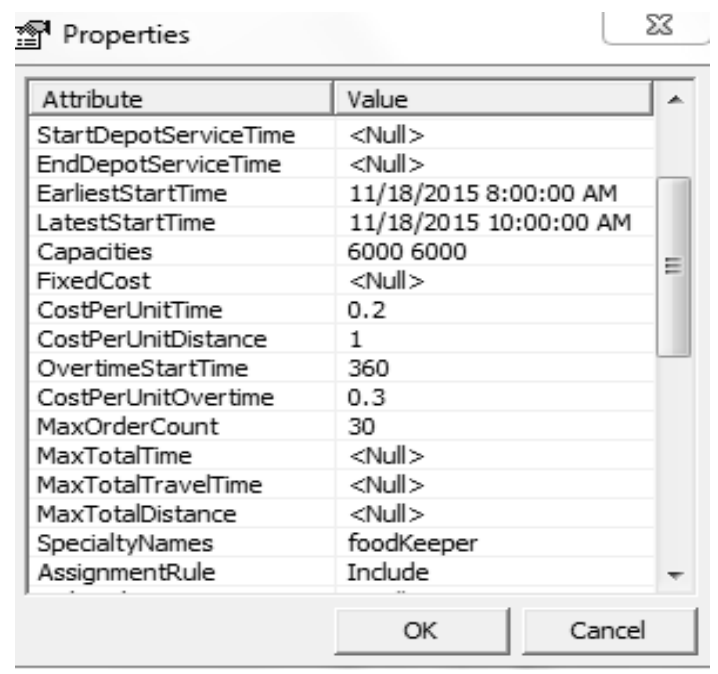

Fig. 5. Properties of routes

\begin{tabular}{|c|c|c|}
\hline \multicolumn{2}{|l|}{ 国 Properties } & $\mathrm{x}$ \\
\hline Attribute & Value & A \\
\hline OrderCount & 14 & \\
\hline TotalCost & 37.753895 & \\
\hline RegularTimeCost & 28.532966 & \\
\hline OvertimeCost & 0 & \\
\hline DistanceCost & 9.220928 & \\
\hline TotalTime & 142.664832 & \\
\hline TotalOrderServiceTime & 35 & \\
\hline TotalBreakServiceTime & 30 & \\
\hline TotalTravelTime & 25.7415 & \\
\hline TotalDistance & 9.220928 & (1) \\
\hline StartTime & 11/18/2015 9:16:21 AM & \\
\hline EndTime & $11 / 18 / 2015$ 11:39:01 AM & \\
\hline TotalWaitTime & 51.923333 & $\equiv$ \\
\hline TotalViolationTime & 0 & \\
\hline RenewalCount & 0 & \\
\hline \multirow[t]{2}{*}{ TotalRenewalServiceTime } & 0 & - \\
\hline & OK & \\
\hline
\end{tabular}

Fig. 6. Calculated fields of Left Route

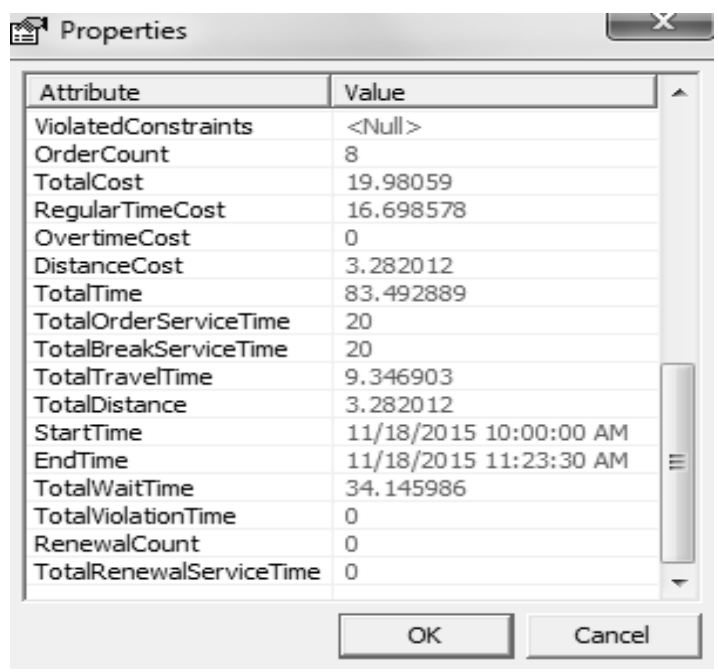

Fig. 7. Calculated fields of Left Route 
Break time of every vehicle is calculated dynamically and appears in directions window of Left Route and Right Route as shown in Fig 8 and Fig 9 consequently. Break time of each vehicle is calculated automatically according to requested orders in this route. As seen break time of the right route differs from the break time of the left route. Break time of the left route starts on 9:37AM and ends on 10:07AM. Break time of the right route starts on 10:35 AM and ends on 10:55 AM. Period of the break on left route is 30 minutes varying from period of the beak on right route which is 20 minutes.

If there is an accident occurred on sidi Hala st, calculated fields and directions of left route are changed automatically as shown in Fig 10, Fig 11.
This means that after adding barriers into system like an accident or fire such as the proposed accident on Sidi Hala st, system regenerates new route directions with alternative paths and recalculated properties again.

The break time on left route is changed automatically to meet all constraints (changed from 9:37 Am and 10:07 Am to be 9:30 Am and 10:00 Am).

As seen total cost field is increased from 37.75 to 39.64 . Also total time is increased from 142.66 to 149.07 . The starting time and ending time is changed. But still there are no violations in time constraints. Directions window of the left route changed and Sidi Hala st was not visited. Resulting route paths before and after barrier is shown in Fig 12.

\begin{tabular}{|c|c|c|c|c|c|c|c|}
\hline \multicolumn{4}{|c|}{ Directions (Vehicle Routing Problem) } & \multicolumn{4}{|c|}{\begin{tabular}{|l|l|l|l|}
$口$ & 回 & $x$ \\
\end{tabular}} \\
\hline & 18: & $9: 30 \mathrm{AM}$ & Make sharp right on Port Said st & $0.1 \mathrm{~km}$ & $<1 \mathrm{~min}$ & Map & A \\
\hline & 19: & $9: 30 \mathrm{AM}$ & $\begin{array}{l}\text { Arrive at Basem (Rice), on the left } \\
\text { Time Window: } 11 / 18 / 2015 \text { 8:00 AM - 11/18/2015 1:30 PM } \\
\text { Service Time: } 3 \mathrm{~min}\end{array}$ & & $3 \mathrm{~min}$ & Map & \\
\hline & $\underline{20}:$ & $9: 33$ AM & Depart Basem (Rice) & & & & \\
\hline & 21: & $9: 33$ AM & Go back southwest on Port Said st & $0.1 \mathrm{~km}$ & $<1 \mathrm{~min}$ & Map & \\
\hline & $\underline{22}:$ & $9: 33$ AM & Make sharp left on Sidi Hala & $0.5 \mathrm{~km}$ & $<1 \mathrm{~min}$ & Map & . \\
\hline & 23: & $9: 34$ AM & Turn right on Al Modier st & $0.5 \mathrm{~km}$ & $1 \mathrm{~min}$ & Map & $\equiv$ \\
\hline & 24: & $9: 35$ AM & Turn left on Khairy Aljojry & & & Map & \\
\hline & $\underline{25}:$ & $9: 35$ AM & $\begin{array}{l}\text { Arrive at Basem (Home), on the left } \\
\text { Time Window: } 11 / 18 / 2015 \text { 8:00 AM - 11/18/2015 1:30 PM } \\
\text { Service Time: } 2 \text { min }\end{array}$ & & $2 \mathrm{~min}$ & Map & \\
\hline & 26: & $9: 37$ AM & Depart Basem (Home) & & & & \\
\hline & 27: & 9:37 AM & $\begin{array}{l}\text { Arrive at Break } \\
\text { Service Time: } 30 \mathrm{~min}\end{array}$ & & $30 \mathrm{~min}$ & Map & \\
\hline \multirow[t]{7}{*}{ 】 } & 28: & 10:07 AM & Depart Break & & & & \\
\hline & 29: & $10: 07 \mathrm{AM}$ & Go back west on Khairy Aljojry & & & Map & \\
\hline & 30: & 10:07 AM & Turn right on Al Modier st & $0.5 \mathrm{~km}$ & $1 \mathrm{~min}$ & Map & \\
\hline & 31: & 10:08 AM & Turn left on Sidi Hala & $0.5 \mathrm{~km}$ & $<1 \min$ & Map & \\
\hline & 32: & $10: 09$ AM & Make sharp right on Port Said st & $0.1 \mathrm{~km}$ & $<1 \min$ & Map & \\
\hline & 33: & $10: 09 \mathrm{AM}$ & $\begin{array}{l}\text { Arrive early at Nagwa (Bread), on the left } \\
\text { Time Window: } 11 / 18 / 201511: 00 \text { AM - 11/18/2015 12:00 PM } \\
\text { Wait Time: } 51 \mathrm{~min} \\
\text { Service Time: } 3 \mathrm{~min}\end{array}$ & & $54 \mathrm{~min}$ & Map & - \\
\hline & Options.. & Print & Preview... & Print & & Close & \\
\hline
\end{tabular}

Fig. 8. Directions of Left Route with dynamic breaktime

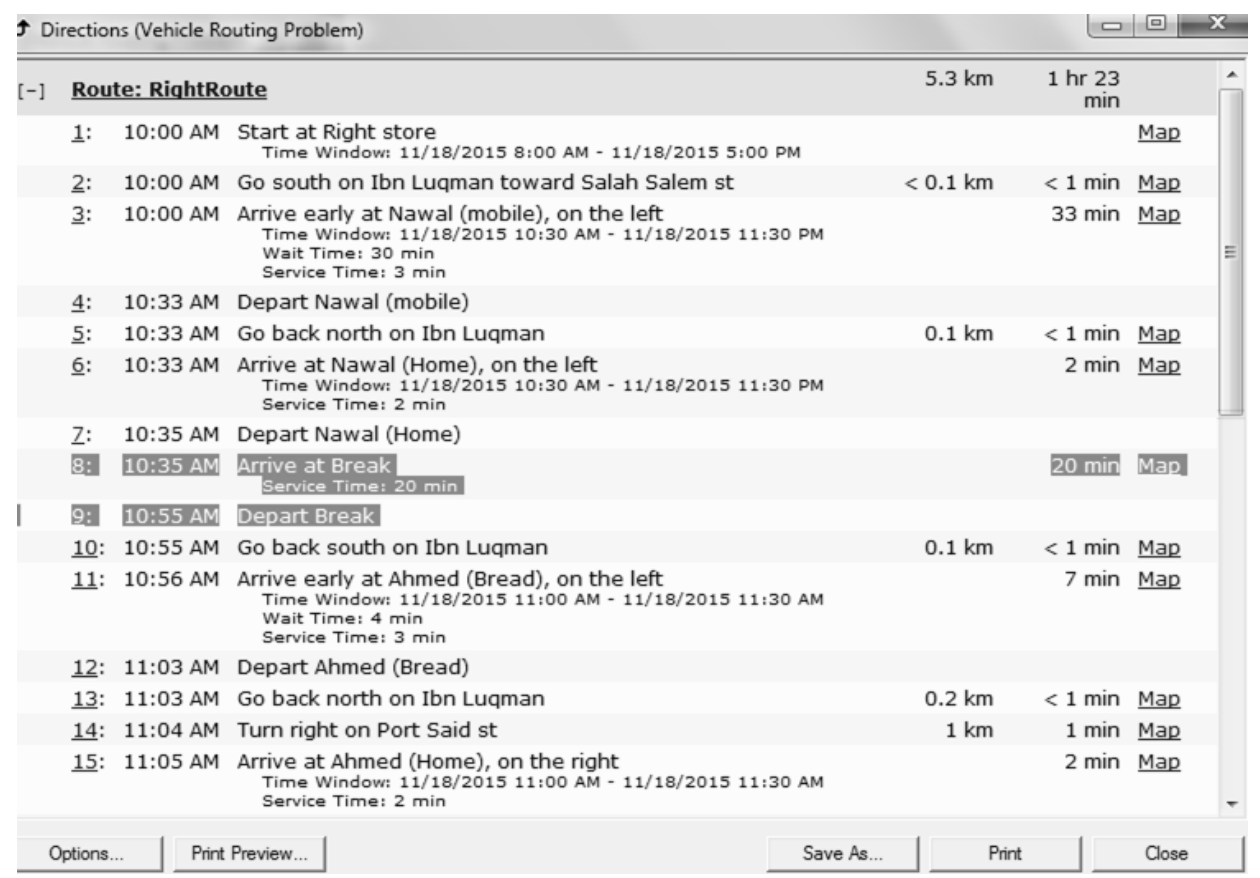

Fig. 9. Directions of Right Route with dynamic breaktime 


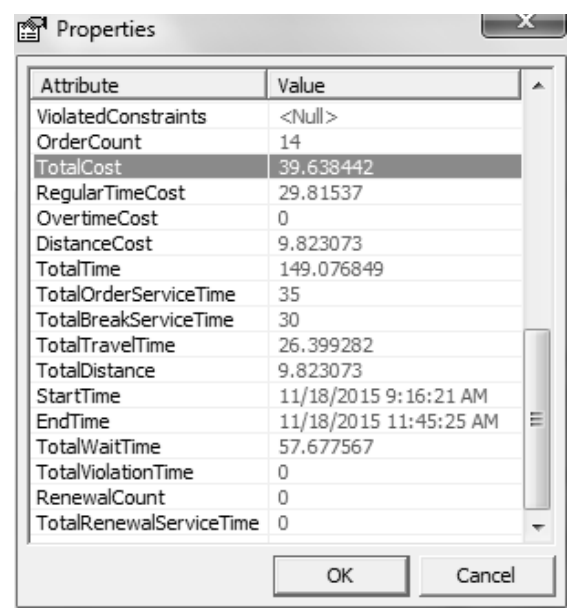

Fig. 10. Calculated fields of Left Route after solving with barriers

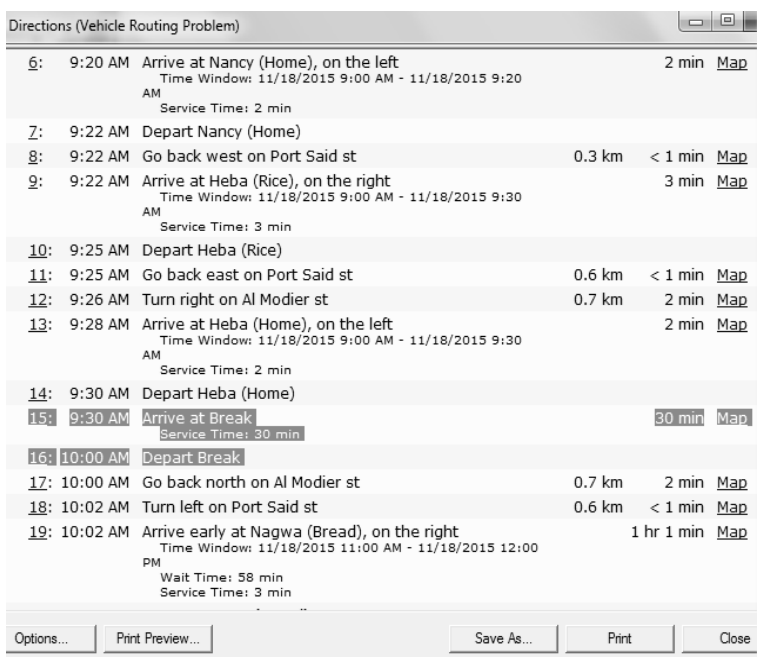

Fig. 11. Left Route before and after barrier

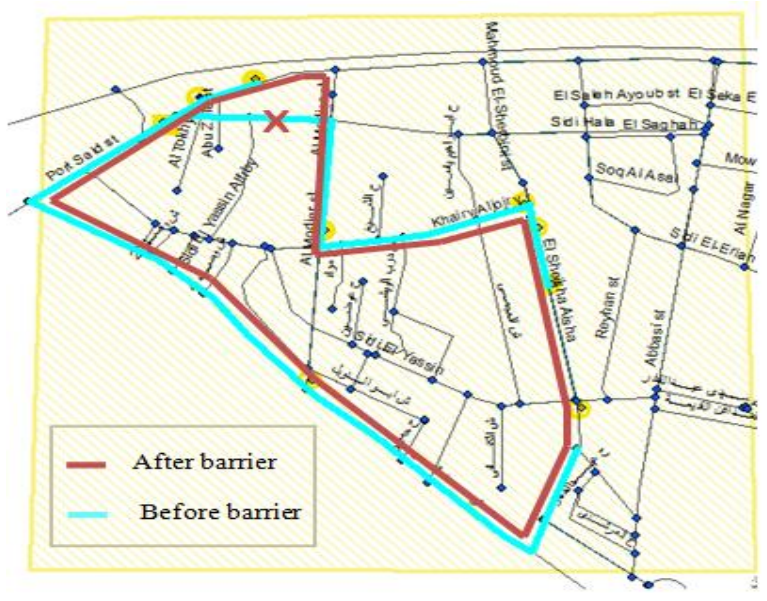

Fig. 12. Directions of Left Route after with barrier

\section{CONCLUSION}

The problem of delivering conditional products in Mansoura city in Egypt is solved based on GIS. Using proposed approach, best route is determined easily as it can be printed and given to drivers to inform them about their schedule. OD cost Matrix is used for optimizing the solution as it calculates the nearest least cost depot to customer's destination to transmit requested orders from that depot to minimize travel time and travel cost. Lunch Break time of drivers are calculated automatically according to conditional products that are assigned to be delivered on every route. When barrier occurred on a street, system resolves the problem again and regenerates alternative route directions without time violations. The break time automatically recalculated and may be changed.

[1]
Esti.
http://www.esri.com/library/bestpractices/what-is-gis.pdf A.Prakash, Geographical Information System, An overview. India: Indian Institute of Information Technology.

[3] P.Keenan, "Modelling vehicle routing in GIS," springer, 2008.

[4] Jean-Paul Rodrigue Shih-Lung Shaw. people.hofstra.edu. [Online]. https://people.hofstra.edu/geotrans/eng/methods/ch1m4en.html

[5] M.E.A.El-Mikkawy, B.T.Shabana A.M.Riad, "Real Time Route for Dynamic Road Congestions," International Journal of Computer Science Issues, 2012.

[6] A.Pandey, K.Pandey, M.Saim V.Shukla, "V.SGIS-BASED SOLUTION OF SCHEDULING AND ROUTING SCHOOL BUSES- A THEORETICAL APPROACH," International conference on technologies for sustainability-Engineering Information technology, 2015.

[7] Yew Soon Ong, Chen Kim Heng, Puay Siew Tan, and Nengsheng Allan Zhang G.Kim, "City Vehicle Routing Problem (City VRP): A Review, IEEE TRANSACTIONS ON INTELLIGENT TRANSPORTATION SYSTEMS," IEEE, 2015.

[8] Michael H. Cole Y.Zhong, "Y.Zhong, Michael H. Cole, "A Simple Approach to Linehaul-Backhaul Problems: A Guided Local Search Approach for the Vehicle Routing Problem".

[9] E.Neftalí Escobar Gómez, F.Taracena Sanz, "THE VEHICLE ROUTING PROBLEM WITH LIMITED VEHICLE CAPACITIES," International Journal for Traffic and Transport Engineering, 2013.

[10] J.Yves Potvin, M.Gendreau J.Francois Cote, "The Vehicle Routing Problem with stochastic Two-Dimensional Items ," CIRRELT, 2013.

[11] S.Krichen S.Faiz, Geographical Information Systems and spatial Optimization., 2013.

[12] Esri. (2016) arcgis.

https://desktop.arcgis.com/en/desktop/latest/guidebooks/extensions/network-analyst/vehicle-routing-problem.htm

[13] Esri. (2009, Dec.) arcgis. [Online]. http://www.arcgis.com/home/item.html?id=3b93337983e9436f8db950e 38a8629af

[14] A.Vienneau, J.Bailey, J.Banning and S.Woo M.Harlow, "ArcGIS 9 Using ArcCatalog," Esri, 1999.

[15] Esri. OD Cost Matrix. [Online] http://webhelp.esri.com/arcgisdesktop/9.3/index.cfm?TopicName=Creati ng_an_OD_cost_matrix

[16] Esri. Types of Network analyst. [Online]. http://webhelp.esri.com/arcgisdesktop/9.3/index.cfm?TopicName=Types _of_network_analyses

[17] G.Mani, K.Pandey H.Shankar, "GIS Based Solution of Multi-Depot Capacitated Vehicle Routing Problem with Time Window Using Tabu Search Algorithm," International Journal of Traffic and Transportation Engineering, 2014.

[18] R.Fauzi, R.Muhamad M.Abousaeidi, "Geographic Information System (GIS) modeling approach to determine the fastest delivery routes," Saudi Journal of Biological Sciences, 2015.

[19] Chih-Hui Shieh, Kai-Ting Chan, Shin-Yi Chiu, Jyun-You Fan, Yu-Ting Chang, Nuo-Jhen Ma Rong-Chang Chen, "A Systematic Approach to Order Fulfillment of On-demand Delivery Service for Bento Industry," ELSEVIER, 2013. 
[20] S.Sumathi Surekha P, "Solution To Multi-Depot Vehicle Routing Problem Using Genetic Algorithms," World Applied Programming journal, August 2011.
[21] Varun Singh, R.C. Vaishya V.K.Purwar, "GEOSPATIAL ANALYSIS OF REGIONAL MILK DISTRIBUTION FOR ALLAHABAD CITY," The International Daily journal, 2015. 